\title{
THE ANTIMICROBIAL PROPERTIES OF EXTRACTS OBTAINED FROM BEGONIA GOEGOENSIS N.E.BR. LEAF AGAINST PSEUDOMONAS AERUGINOSA ISOLATES
}

\author{
Tkachenko Halyna $^{1 *}$, Buyun Lyudmyla ${ }^{2}$, Osadowski Zbigniew ${ }^{1}$ \\ ${ }^{1}$ Institute of Biology and Environmental Protection, Pomeranian University in Słupsk, Poland \\ ${ }^{2}$ M.M. Gryshko National Botanical Garden, National Academy of Science of Ukraine, Kyiv, Ukraine \\ Received 25.6. 2017 \\ Revised 29. 6. 2017 \\ Published 30.11. 2017
}

The present study was designed to evaluate the antibacterial property of crude extracts of the leaves of Begonia goegoensis N.E.Br. prepared in different solvent systems against Pseudomonas aeruginosa (ATCC 27583) and $\beta$-lactamases producing Pseudomonas aeruginosa (MBL-positive Pseudomonas aeruginosa) strains. Therefore, five kinds of solvents were used to extract the active ingredients from the leaves of Begonia goegoensis: ethanol, methanol, ethyl acetate, hexane, and dichloromethane. The testing of antibacterial activity of the plant extracts was carried out in vitro by Kirby-Bauer disc diffusion technique. Subsequently, the present study has shown that ethanolic extract from the leaves of Begonia goegoensis exhibited strong activity against Pseudomonas aeruginosa (inhibition zone diameter ranged from $12 \mathrm{~mm}$ to $13 \mathrm{~mm}$ ), while methanolic leaf extract screened revealed less profound activity (within 11-12.5 mm). Moreover, it has been observed that ethyl acetate, hexane and dichloromethane extracts obtained from leaves of Begonia goegoensis revealed no antibacterial activity against $P$. aeruginosa and MBL-positive Pseudomonas aeruginosa strains. MBL-positive Pseudomonas aeruginosa was also susceptible to ethanolic and methanolic extracts (inhibition zone diameter ranged from $12.5 \mathrm{~mm}$ to $15.5 \mathrm{~mm}$ ). Thus, the spectrum of activity observed in the present study indicate that the alcoholic leaf extract of Begonia goegoensis could be a possible source to obtain new and effective herbal medicines to treat various infectious diseases, including infections, caused by drug resistant microorganisms.

Keywords: Pseudomonas aeruginosa; Begonia goegoensis; leaf extract; antimicrobial activity ; Kirby-Bauer disc diffusion technique

\section{Introduction}

Pseudomonas aeruginosa is an infectious bacterial species, capable to infecting and promoting disease in different tissues, and responsible for remarkable morbidity and mortality rates in humans (Doosti et al., 2013). Several mechanisms are involved in Pseudomonas aeruginosa resistance to antimicrobial agents, such as chromosomal expression of resistance encoding genes, $\beta$-lactamase production, efflux pumps and a decrease in membrane permeability (Rodrigues et al., 2011; Doosti et al. 2013). One of the mechanisms of resistance to carbapenem antibiotics in Pseudomonas aeruginosa is metallo- $\beta$-lactamases (MBL) production that hydrolyzes all carbapenems (Lepsanovic et al., 2008; Chin et al., 2011; Doosti et al., 2013).

*Corresponding author: Halyna Tkachenko, Institute of Biology and Environmental Protection, Pomeranian University in Slupsk, Poland, $₫$ tkachenko@apsl.edu.pl 
In the past years, the pharmaceutical industry has been focused mainly on libraries of synthetic compounds as drug discovery source. However, at the same time a declining trend in the number of new drugs reaching the market has been observed, raising renewed scientific interest in drug discovery from natural sources despite its known advantages and benefits, e.g. cost-effectiveness and global availability as well as their safety compared to other medicinal products and the lack of major side-effects (Atanasov et al., 2015; Yamani et al., 2016).

Medicinal plants have a great potential as antimicrobial compounds sources against microorganisms for providing novel drug leads with the proven mechanism of action (Singh et al., 2012; Venkatadri et al., 2015). Moreover, plant extracts can be used in the treatment of infectious diseases caused by drug resistant microorganisms (Venkatadri et al., 2015).

Begonia L. is one of the most species-rich angiosperm genera with approximately 1500 species currently recognized (Frodin, 2004). Within the genus Begonia, there is a large range of morphological diversity, particularly in vegetative form, and this is linked to adaptation to a variety of ecological conditions. Vegetative adaptations such as the evolution of perennial rhizomes, leaf micromorphology optimized for low, scattered light; or stomatal clustering may underlie their ability to thrive in diverse niches (Dewitte et al., 2011).

Begonia species are globally important ornamental plants widely used in cultivation. However, in their native environments, many Begonia species are rare and threatened by deforestation (Chan et al., 2015). Since Begonia genus is widespread in tropical regions of the world, its species have been used by local people as folk or traditional herbal medicines. Moreover, phytochemical investigations of Begonia species have revealed that many compounds, isolated from this genus are highly bioactive (Tsybulya et al., 2010; Karpova et al., 2011).

Consequently, in the present work, extracts prepared in different solvent systems obtained from crude leaves of Begonia goegoensis N.E.Br. were evaluated for its antibacterial property against Pseudomonas aeruginosa (ATCC 27583) and $\beta$-lactamases producing Pseudomonas aeruginosa (MBLpositive Pseudomonas aeruginosa). This Begonia species belonging to Begoniaceae family has been selected, because the antimicrobial activity of Begonia species has been well studied (Tsybulya et al., 2010; Karpova et al., 2011).

\section{Materials and methodology}

\section{Collection of Plant Material}

The leaves of Begonia goegoensis (Figure 1) plants, cultivated under glasshouse conditions, were sampled at M.M. Gryshko National Botanical Garden, National Academy of Science of Ukraine.

\section{Preparation of Plant Extracts}

Freshly sampled leaves were washed, weighted, crushed, and homogenized in $96 \%$ ethanol, methanol, ethyl acetate, hexane, and dichloromethane (in ratio $1: 19$ ) at room temperature. All extracts were stored at $4{ }^{\circ} \mathrm{C}$ until use.

\section{Bacterial Growth Inhibition Test of Plant Extracts by the Disk Diffusion Method}

The antimicrobial activity of the extract was evaluated by the agar disk diffusion assay (Bauer et al., 1966). Strains of Pseudomonas aeruginosa (ATCC 27583) and locally isolated MBL-positive Pseudomonas aeruginosa were suspended in sterile solution of $0.9 \%$ normal saline and the turbidity adjusted equivalent to that of a 0.5 McFarland standard. Culture was inoculated onto Mueller-Hinton 
(MH) agar plates. Sterile filter paper discs impregnated with extracts were applied over each of the culture plates. Isolates of bacteria were then incubated at $37^{\circ} \mathrm{C}$ for $24 \mathrm{~h}$. The plates were then observed for the zone of inhibition produced by the antibacterial activity of extracts obtained from leaves of Begonia goegoensis. Negative control discs impregnated with sterile ethanol, methanol, ethyl acetate, hexane, and dichloromethane were used in each experiment. The antimicrobial activities of the extracts tested were evaluated at the end of the inoculated period. At the end of the incubation period, the diameters of zones of inhibition were measured and photographs were taken. All assays were repeated in six replicates and the mean zones of inhibition were recorded. All statistical calculations were performed on separate data from each bacterial strains and extracts. The following zone diameter criteria were used to assign susceptibility or resistance of bacteria to the phytochemicals tested: Susceptible $(S) \geq 15 \mathrm{~mm}$, Intermediate $(I)=11-14 \mathrm{~mm}$, and Resistant $(R) \leq 10 \mathrm{~mm}$ (Okoth et al., 2013).
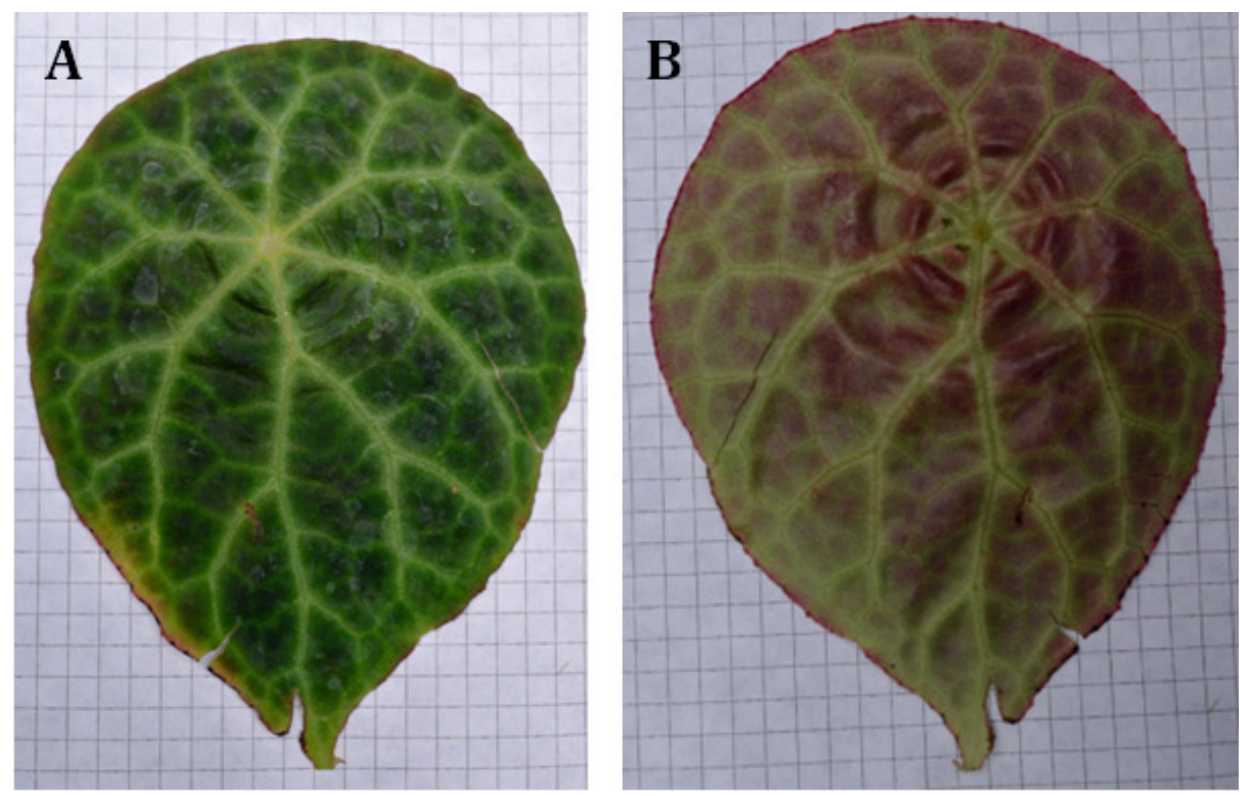

Figure 1

Leaf morphology of Begonia goegoensis N.E.Br.

A - adaxial leaf surface; $B$ - abaxial leaf surface

\section{Results and discussion}

Antimicrobial activity of various extracts obtained from leaves of Begonia goegoensis against Pseudomonas aeruginosa and MBL-positive Pseudomonas aeruginosa measured as diameters of zones of inhibition was presented in Figure 2 and 3.

The present study has shown that ethanolic extract from the leaves of Begonia goegoensis exhibited strong activity against Pseudomonas aeruginosa (inhibition zone diameter ranged from $12 \mathrm{~mm}$ to $13 \mathrm{~mm}$ ), while a methanolic extract from leaves revealed less activity (11 and $12.5 \mathrm{~mm}$ ) (Figure 2 and 3).

Moreover, it has been observed that ethyl acetate, hexane and dichloromethane extracts obtained from leaves of Begonia goegoensis revealed no antibacterial activity against $P$ seudomonas aeruginosa and MBL-positive P. aeruginosa. MBL-positive Pseudomonas aeruginosa was also susceptible to 
ethanolic and methanolic extracts (inhibition zone diameter ranged from $12.5 \mathrm{~mm}$ to $15.5 \mathrm{~mm}$ ) (Figure 2 and 3).

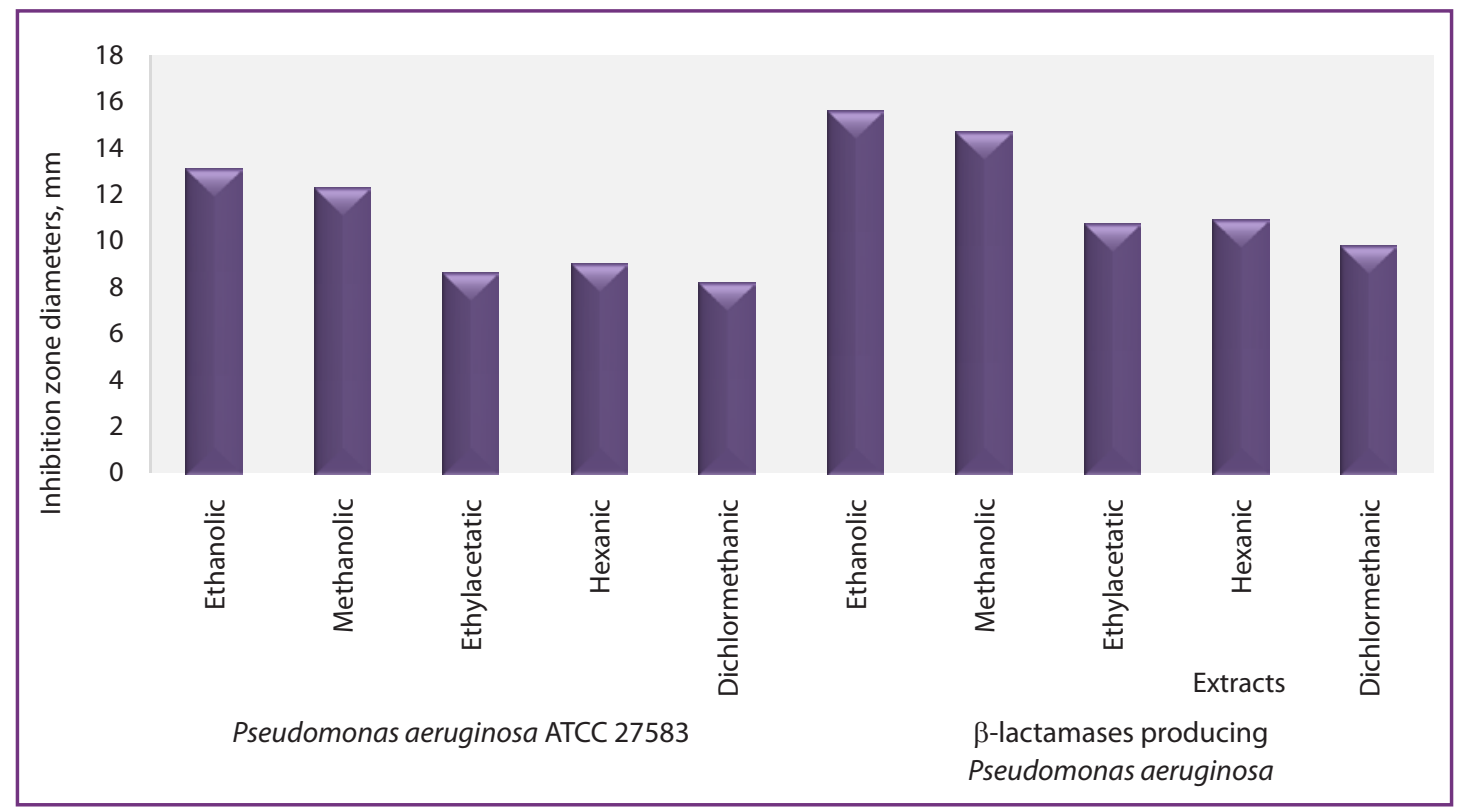

Figure 2 Antimicrobial activity of various extracts obtained from leaves of Begonia goegoensis N.E.Br. against Pseudomonas aeruginosa and MBL-positive Pseudomonas aeruginosa measured as diameters of zones of inhibition

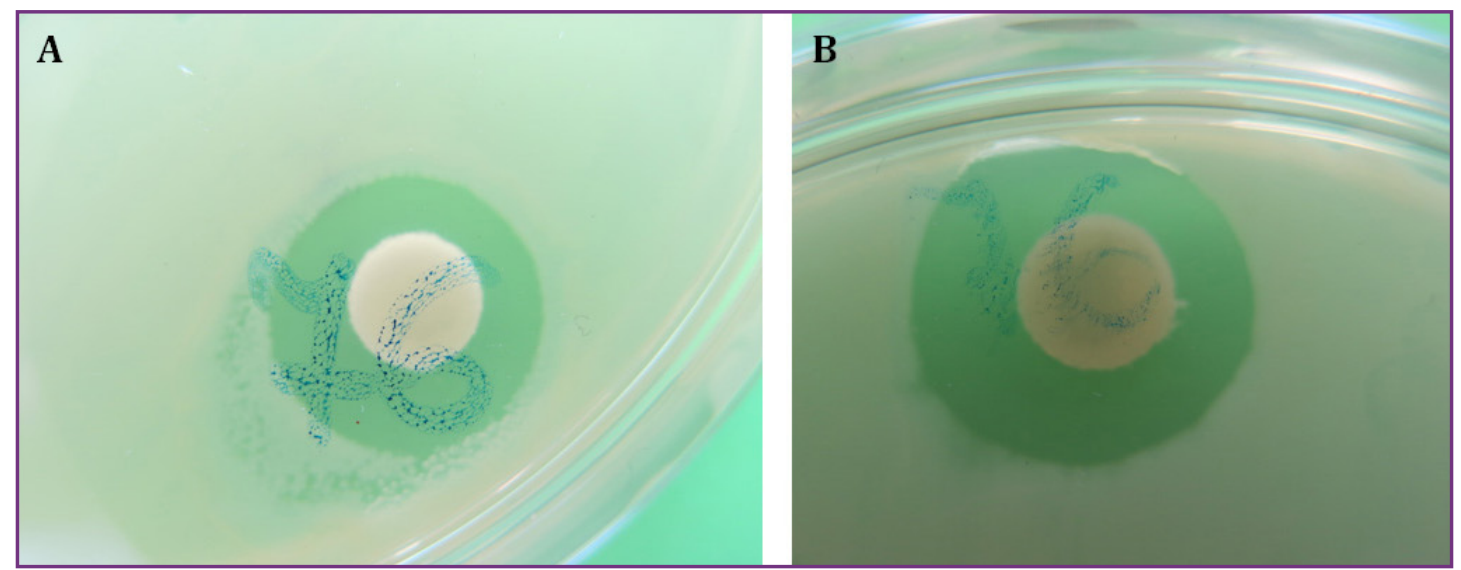

Figure 3 Antibacterial spectrum of ethanolic extracts obtained from leaves of Begonia goegoensis N.E.Br. against Pseudomonas aeruginosa (A) and MBL-positive Pseudomonas aeruginosa (B)

These results are in line with findings of Suresh and Nagarajan (2009) who have found similar data due to a screening of antimicrobial efficacy of other Begonia species against Gram-positive and Gram-negative bacteria as well as fungi. Aqueous extracts of Begonia malabarica Lam. leaves showed antimicrobial activity which is more profound against fungal strains than the bacterial strains. Moreover, the maximum activity was observed against Vibrio cholerae, whereas among 
the fungal strains the most susceptible to plant extract screened was Aspergillus niger (Suresh and Nagarajan, 2009). In another study, aqueous leaves extract showed antimicrobial activity against the Gram-negative bacteria except for Vibrio parahaemolyticus. Nevertheless, the chloroform and methanol extracts showed minimum activity against all the tested bacteria (Ramesh et al., 2002). The antibacterial activity of methanolic extracts of Begonia floccifera Bedd. flowers against Escherichia coli, Klebsiella pneumonia, Pseudomonas aeruginosa, Staphylococcus aureus, Bacillus cereus, Salmonella typhi, Serratia marcescens, Proteus mirabilis, Enterococcus faecalis and Streptococcus pyogenes were investigated by Jeeva et al. (2012). In addition, the results of the phytochemical screening, conducted by these authors, revealed that extract of Begonia floccifera flowers screened contained phenol, tannins, xanthoproteins, steroids, tannins, steroids, phytosterols, triterpenoids, sapogenins, coumarins and carbohydrates. Interestingly, the bacteria tested have exhibited susceptibility to methanolic extracts of Begonia floccifera in varied degree. For example, the maximum zone of inhibition was $28 \mathrm{~mm}$ for Bacillus cereus, $25 \mathrm{~mm}$ for Staphylococcus aureus, $15 \mathrm{~mm}$ for Escherichia coli, $13 \mathrm{~mm}$ for Proteus mirabilis, $7 \mathrm{~mm}$ for Klebsiella pneumonia. Therefore, the antimicrobial activity of methanolic extracts of $\mathrm{B}$. floccifera flowers against various bacteria tested is comparable and their potential as an alternative in the treatment of infections caused by these microorganisms is of great importance (Jeeva et al., 2012).

The preliminary phytochemical studies of Begonia malabarica by Ramesh and co-workers (2002) revealed the presence of flavone, sterol, triterpene in hexane, chloroform, and methanol extracts; phenol in chloroform and methanol extracts and quinone, saponin, tannin and starch in methanol extract. All the extracts did not answer for alkaloid. Flavones are becoming the subject of antimicrobial study and many groups have isolated and identified different flavones possessing antifungal, antiviral and antibacterial activity. Nitrogen containing flavones have been reported to have considerable antimicrobial activity. The compounds, bearing amino alkyl, cyano- or alkenyl alkyl group on piperazine are found to be the potent antibacterial and antifungal agents (Singh et al., 2014). Cushnie and Lamb (2005) revealed that flavonoids possess capabilities to form complexes with extracellular soluble protein and bacterial cells.

Catechins also posed antibacterial potential via DNA gyrase prohibition operations. It is also worth noting that catechins could enhance the sensitivity of bacterial antibiotic resistance to other kinds of antibiotics, such as tetracycline and $\beta$-lactam, by rehabilitating the repressors sensitivity (Stapleton et al., 2004).

Three new compounds: begonanline, nantoamide and methyl (S)-glycerate, as well as forty-four known compounds have been isolated and characterized from the rhizomes of Begonia nantoensis by Wu and co-workers (2004). Some of them showed cytotoxicity against four human cancer cell lines and demonstrated significant activity against HIV replication in H9 lymphocyte cells (Wu et al., 2004). Ramesh and co-workers (2002) have observed that hexane, chloroform and methanolic extracts of the leaves of Begonia malabarica did not exhibit of antifungal activity against the Aspergillus flavus, Aspergillus fumigatus, Aspergillus niger and Candida albicans. Moreover, the hexane extract did not show antibacterial activity also. The significant activity against Klebsiella pneumoniae, Pseudomonas aeruginosa, Staphylococcus aureus shown by chloroform and methanolic extracts implicates the use of the plant in respiratory tract diseases by the tribals. The activity of the same extracts against Vibrio parahaemolyticus suggests the use of the plant in diarrhea. The activity of the chloroform and aqueous extracts against Chromobacterium violaceum supports the use of plant against skin lesions and pyemia (Ramesh et al., 2002). 
Moreover, we also investigated the anti-Escherichia coli activity of the ethanolic extracts from the leaves of Begonia species plants, cultivated under glasshouse conditions at M.M. Gryshko National Botanical Garden (NBG), National Academy of Science of Ukraine (Tkachenko et al., 2016). Our previous study has shown that ethanolic extracts obtained from leaves of Begonia species had moderate activity against E. coli. The diameters of inhibition zone for Begonia solimutata L.B.Sm. \& Wassh. were $14 \mathrm{~mm}, 11.5 \mathrm{~mm}$ for Begonia goegoensis N.E. Br., $13 \mathrm{~mm}$ for Begonia foliosa Kunth, $13.5 \mathrm{~mm}$ for Begonia $\times$ bunchii L.H. Bailey $15 \mathrm{~mm}$ for Begonia thiemei C.DC., $19 \mathrm{~mm}$ for Begonia peltata Otto \& Dietr., $12 \mathrm{~mm}$ for Begonia heracleifolia Cham. \& Schltdl., $11.5 \mathrm{~mm}$ for Begonia dregei Otto \& Dietr., and $16 \mathrm{~mm}$ for Begonia mexicana G. Karst ex Fotsch. The highest antimicrobial effect was recorded for Begonia peltata, Begonia mexicana, and Begonia thiemei. The most antimicrobially effective plant against Escherichia coli was Begonia peltata, being highly active with the ethanolic extract (diameter of inhibition zone was $19 \mathrm{~mm}$ ). The highly active antimicrobial effects noted against Gram-positive and Gram-negative bacteria are worthy of highlighting (Tkachenko et al., 2016).

\section{Conclusions}

This study emphasizes the importance of ethanolic extract of Begonia goegoensis as effective antimicrobial agents against Pseudomonas aeruginosa and $\beta$-lactamases producing Pseudomonas aeruginosa. The plant studied here had shown that it is potentially rich in antimicrobial compounds. The use of Begonia species in medicine and veterinary suggests that they represent an economic and safe alternative for treatment of resistant microorganisms. Since this is a small study, a further and larger scale investigation of the efficacy of extracts prepared from other Begonia species as well as with various solvents, is necessary to confirm these results.

\section{References}

Atanasov, A.G, Waltenberger, B., Pferschy-Wenzig, E.M, Linder, T., Wawrosch, C., Uhrin, P., Temml, V., Wang, L., Schwaiger, S. et al. 2015. Discovery and resupply of pharmacologically active plant-derived natural products: A review. Biotechnol. Adv., vol. 33, no. 8, p. 1582-1614. DOI: 10.1016/j.biotechadv.2015.08.001

Bauer, A.W., Kirby, W.M., Sherris, J.C., Turck, M. 1966. Antibiotic susceptibility testing by a standardized single disk method. Am. J. Clin. Pathol., vol. 45, no. 4, p. 493-496.

Chan, Y.M., Twyford, A.D., Tnah, L.H., Lee, C.T. 2015. Characterisation of EST-SSR markers for Begonia maxwelliana (Begoniaceae) and cross-amplification in 23 species from 7 Asian sections. Scientia, vol. 190, p. 70-74. DOI: 10.1016/j.scienta.2015.04.012

Chin, B.S., Han, S.H., Choi, S.H., Lee, H.S., Jeong, S.J., Choi, H.K., Choi, J.Y., Song, Y.G., Kim, C.K., Yong, D., Lee, K., Kim, J.M. 2011. The characteristics of metallo-beta-lactamase-producing gram-negative bacilli isolated from sputum and urine: a single center experience in Korea. Yonsei Med. J., vol. 52, no. 2, p. 351-357. DOI: 10.3349/ymj.2011.52.2.351

Cushnie, T.P., Lamb, A.J. 2005. Detection of galangin-induced cytoplasmic membrane damage in Staphylococcus aureus by measuring potassium loss. J. Ethnopharmacol., vol. 101, no. 1-3, p. 243-248. DOI: 10.1016/j.jep.2005.04.014.

Dewitte, A., Twyford, A.D., Thomas, D.C., Kidner, C.A., Van Huylenbroeck, J. 2011. The origin of diversity in Begonia: genome dynamism, population processes and phylogenetic patterns. Venora, G, Grillo, O., López-Pujol, J. The Dynamical Processes of Biodiversity-Case Studies of Evolution and Spatial Distribution. Croatia, Intech Press, Rijeka, p. 27-52. DOI: 10.5772/23789

Doosti, M., Ramazani, A., Garshasbi, M. 2013. Identification and characterization of metallo- $\beta$-lactamases producing Pseudomonas aeruginosa clinical isolates in University Hospital from Zanjan Province, Iran. Iran Biomed. J., vol. 17, no. 3, p. 129-133. DOI: 10.6091/ibj.1107.2013 
Frodin, D.G. 2004. History and concepts of big plant genera. Taxon, vol. 53, p. 753-776. DOI: $10.2307 / 4135449$

Jeeva, S., Marimuthu, J., Antonisamy, J. 2012. Anti-bacterial and phytochemical studies on methanolic extracts of Begonia floccifera Bedd. flower. Asian Pacific Journal of Tropical Biomedicine, p. S151-S154. DOI: 10.1016/S2221-1691(12)60147-6

Karpova E.A., Tsybula, N.V. Kchramova E.P., Yakimova, Y.L., Fershalova, T.D. 2011. Antimicrobial activity and flavonoids content of some representatives of genus Begonia L. used in phytodesign. Voprosy biologicheskoy, meditsinskoy i farmatsevticheskoy khimii, no. 1, p. 8-17.

Lepsanovich, Z., Libisch, B., Tomanovic, B., Nonkovici, Z., Balogh, B., Fuzi, M. 2008. Characterisation of the first VIM metallo-beta-lactamase-producing Pseudomonas aeruginosa clinical isolate in Serbia. Acta Microbiol. Immunol. Hung., vol. 55, no. 4, p. 447-454. DOI: 10.1556/AMicr.55.2008.4.9

Okoth, D.A., Chenia, H.Y., Koorbanally, N.A. 2013. Antibacterial and antioxidant activities of flavonoids from Lannea alata (Engl.) Engl. (Anacardiaceae). Phytochem. Lett., vol. 6, p. 476-481. DOI: 10.1016/j. phytol.2013.06.003

Ramesh N., Viswanathan M.B., Saraswathy A., Balakrishna K., Brindha P., Lakshmanaperumalsamy, P. 2002. Phytochemical and antimicrobial studies of Begonia malabarica. J. Ethnopharmacol., vol. 79, no. 1, p. 129-132. DOI: 10.1016/S0378-8741(01)00352-X

Rodrigues, A.C., Chang, M.R., Nóbrega, G.D., Rodrigues, M.S., Carvalho, N.C., Gomes, B.G., Almeida, D.L. et al. 2011. Metallo-beta-lactamase and genetic diversity of Pseudomonas aeruginosa in intensive care units in Campo Grande, MS, Brazil. Braz. J. Infect. Dis., vol. 15, no. 3, p. 195-199. DOI: 10.1016/ S1413-8670(11)70174-X.

Singh, A.G., Kumar, A., Tewari, D.D. 2012. An ethnobotanical survey of medicinal plants used in Terai forest of western Nepal. J. Ethnobiol. Ethnomed., vol. 8, p. 19. DOI: 10.1186/1746-4269-8-19

Singh, M., Kaur, M., Silakari, O. 2014. Flavones: an important scaffold for medicinal chemistry. Eur. J. Med. Chem., vol. 84, p. 206-239. DOI: 10.1016/j.ejmech.2014.07.013

Stapleton, P.D., Shah, S., Anderson, J.C., Hara, Y., Hamilton-Miller, J.M., Taylor, P.W. 2004. Modulation of betalactam resistance in Staphylococcus aureus by catechins and gallates. Int. J. Antimicrob. Agents, vol. 23, no. 5, p. 462-467. DOI: 10.1016/j.jjantimicag.2003.09.027

Suresh, S.N., Nagarajan, N. 2009. Preliminary phytochemical and antimicrobial activity analysis of Begonia malabarica. LAM J. Basic Appl. Biol., vol. 3, no. 1-2, p. 59-61.

Tkachenko, H., Buyun, L., Osadowski, Z., Belayeva, Ya. 2016. In vitro microbiological investigation of ethanolic extracts obtained from leaves of various Begonia species against Escherichia coli. Słupskie Prace Biologiczne, vol. 13, p. 277-294.

Tsybulya, N.V., Fershalova, T.D., Yakimova, Yu.L. 2010. Examination of the antimicrobial activity of some Begonia L. species as a possible piece of phytodesign. Aerokosmicheskaya i ekologicheskaya meditsina, vol. 44, no. 1, p. 47-50.

Venkatadri, B., Arunagirinathan, N., Rameshkumar, M.R., Ramesh, L., Dhanasezhian, A., Agastian, P. 2015. In vitro Antibacterial Activity of Aqueous and Ethanol Extracts of Aristolochia indica and Toddalia asiatica Against Multidrug-Resistant Bacteria. Indian J. Pharm. Sci., vol. 77, no. 6, p. 788-791. DOI: 10.4103/0250-474X.174991

Wu, P.L., Lin, F.W., Wu, T.S., Kuoh, C.S., Lee, K.H., Lee, S.J. 2004. Cytotoxic and anti-HIV principles from the rhizomes of Begonia nantoensis. Chem. Pharm. Bull. (Tokyo), vol. 52, no. 3, p. 345-349.

Yamani, H.A., Pang, E.C., Mantri, N., Deighton, M.A. 2016. Antimicrobial Activity of Tulsi (Ocimum tenuiflorum) Essential Oil and Their Major Constituents against Three Species of Bacteria. Front Microbiol., vol. 7, p. 681. DOI: 10.3389/fmicb.2016.00681 